\title{
Pentosan Polysulfate
}

National Cancer Institute

\section{Source}

National Cancer Institute. Pentosan Polysulfate. NCI Thesaurus. Code C1755.

A semisynthetic heparin-like glucosaminoglycan. Although its mechanism of action is unknown, pentosan polysulfate may act as a buffer to control cell permeability by preventing irritating solutes from reaching cells coated with it. Administered orally, excreted pentosan polysulfate adheres to the urinary bladder wall, preventing irritants from entering bladder cells and the development or prog ression of interstitial cystitis (IC), a complication of some chemotherapies. This agent also exhibits anticoagulant and fibrinolytic properties. ( $\mathrm{NCl} 04)$ 